\title{
REVIEW
}

\section{Beyond corticosteroids: future prospects in the management of inflammation in COPD}

\author{
N. Roche, R. Marthan, P. Berger, A. Chambellan, P. Chanez, B. Aguilaniu, P-Y. Brillet, \\ P-R. Burgel, A. Chaouat, P. Devillier, R. Escamilla, R. Louis, H. Mal, J-F. Muir, \\ T. Pérez, T. Similowski, B. Wallaert and M. Aubier
}

ABSTRACT: Inflammation plays a central role in the pathophysiology of chronic obstructive pulmonary disease (COPD). Exposure to cigarette smoke induces the recruitment of inflammatory cells in the airways and stimulates innate and adaptive immune mechanisms. Airway inflammation is involved in increased bronchial wall thickness, increased bronchial smooth muscle tone, mucus hypersecretion and loss of parenchymal elastic structures. Oxidative stress impairs tissue integrity, accelerates lung ageing and reduces the efficacy of corticosteroids by decreasing levels of histone deacetylase-2. Protease-antiprotease imbalance impairs tissues and is involved in inflammatory processes. Inflammation is also present in the pulmonary artery wall and at the systemic level in COPD patients, and may be involved in COPD-associated comorbidities.

Proximal airways inflammation contributes to symptoms of chronic bronchitis while distal and parenchymal inflammation relates to airflow obstruction, emphysema and hyperinflation. Basal levels of airways and systemic inflammation are increased in frequent exacerbators.

Inhaled corticosteroids are much less effective in COPD than in asthma, which relates to the intrinsically poor reversibility of COPD-related airflow obstruction and to molecular mechanisms of resistance relating to oxidative stress. Ongoing research aims at developing new drugs targeting more intimately COPD-specific mechanisms of inflammation, hypersecretion and tissue destruction and repair. Among new anti-inflammatory agents, phosphodiesterase-4 inhibitors have been the first to emerge.

KEYWORDS: Chronic obstructive pulmonary disease, inflammation, mucus hypersecretion, phosphodiesterase-4 inhibitors, repair, treatment

I flammation is unanimously agreed to play a central role in chronic obstructive pulmonary disease (COPD) pathology, but is less responsive to corticosteroids than asthma, in which the characteristics of inflammation are different. Over the past $15 \mathrm{yrs}$, the development of exercise rehabilitation, new molecules to help smoking cessation and various drugs (including $\beta 2$-agonist or anticholinergic long-acting bronchodilators, and fixed combinations of long-acting $\beta 2$-agonists and corticosteroids) has led to significant progress in COPD management. Indeed, long-acting bronchodilators represent the first line of pharmacological COPD treatment and are of value in all patients who require symptom relief or prevention on a regular basis. Both $\beta 2$-agonists and anticholinergic agents have been shown to exert anti-inflammatory effects in vitro. However, the clinical relevance of these effects is not clear, which does not prevent them from being effective at improving respiratory mechanics, relieving dyspnoea, increasing exercise tolerance, preventing exacerbations and improving quality of life [1-3]. Effects on lung function decline and mortality remain a matter of debate $[1,2]$.

Even so, several needs are still largely unmet: the impairment in quality of life due to dyspnoearelated reduction in exercise tolerance and exacerbations remains incompletely controlled by current treatments, which are unable to reverse anatomic airway (remodelling) and parenchymal lesions (emphysema).

Pharmacologic progress in COPD will depend on improved knowledge of the pathophysiology of the disease and consequent biological and clinical phenotypes. In November 2009, a group of 18 French-speaking COPD experts met to discuss the
AFFILIATIONS

For a full list of affiliations please refer to the Acknowledgements section.

CORRESPONDENCE

N. Roche

Service de Pneumologie et

Réanimation

Hôtel Dieu

1 Place du Parvis Notre-Dame

75004 Paris Cedex 4

France

E-mail: nicolas.roche@htd.aphp.fr

Received

May 112011

Accepted after revision:

June 202011

PROVENANCE

Publication of this peer-reviewed article was sponsored by Nycomed, France (article sponsor, European Respiratory Review issue 121). 
relationships between inflammation and COPD and possible new tools to treat COPD inflammation [4-6].

\section{COPD AND INFLAMMATION: THE RELATIONSHIP IS CERTAIN BUT INCOMPLETELY UNDERSTOOD}

It is now clear that the development of COPD is associated with chronic bronchial and pulmonary inflammation. Inhaled toxic gases and particles, generally from cigarette smoke (primary cause of COPD), target the bronchial and alveolar epithelium, activating it and inducing recruitment of inflammatory and immune cells in the bronchial mucosa and deep lung [7]. The presence of nonspecific (neutrophils and macrophages) and adaptive (T-lymphocytes) immune cells and their persistence even after smoking cessation [8] suggests that, in some predisposed subjects, cigarette smoke directly or indirectly stimulates memory cells of adaptive immunity [9]. In patients with COPD, lung infiltration by dendritic cells contributes to maintaining an inappropriate adaptive immune response which induces chronic inflammation and lung tissue remodelling. Indeed, expression of co-stimulatory molecules at the surface of dendritic cells correlates with COPD severity (Global initiative for Chronic Obstructive Lung Disease (GOLD) classification) [10]. In COPD patients, mature lymphoid follicles with a germinal centre and well defined $\mathrm{T}$ - and B-lymphocyte areas in the peribronchiolar tissue reflect this adaptive immune response. B-lymphocytes isolated from these follicles are oligoclonal, suggesting antigen-specific induction $[11,12]$. The antigens underlying these immune responses may be microbial antigens, cigarette smoke components, or auto-antigens related to epithelial or extracellular matrix degradation products.
The relationship of inflammation to structural and functional abnormalities has been consistently confirmed [8]. Airway inflammation alters bronchial structure-function relationships in COPD patients via four main mechanisms, the relative importance of which varies from patient to patient: 1) increased bronchial wall thickness, 2) increased bronchial smooth muscle tone, 3) mucus hypersecretion, and 4) loss of elastic structures (fig. 1). These abnormalities are mainly induced by a protease/ antiprotease imbalance and oxidative stress, which also reduces the effect of corticosteroids on the cellular inflammation and cytokine levels in COPD patients' airways.

Oxidative stress is defined by an oxidant-antioxidant imbalance. It plays an important role in the induction and persistence of tissue damage in COPD [14]. There are multiple sources of reactive oxygen species: environmental (e.g. smoking), local (activated alveolar macrophages and neutrophils), and intracellular (aerobic metabolism controlled by mitochondrial respiration). In this sense, oxidative stress is an adaptive response triggering the immune response by nuclear factor- $\kappa \mathrm{B}$ and activator protein-1 activation, so as to neutralise infectious agents and conserve intracellular redox balance, notably via the glutathione system [15]. Intense and persistent oxidative stress over the long term, however, impairs tissue integrity through various mechanisms, including protease/antiprotease imbalance, accelerated ageing, lipid peroxidation and vascular endothelial growth factor pathway alteration. Thus, reactive oxygen species are implicated in: mucus hypersecretion and impaired mucociliary clearance; fibroblast proliferation and

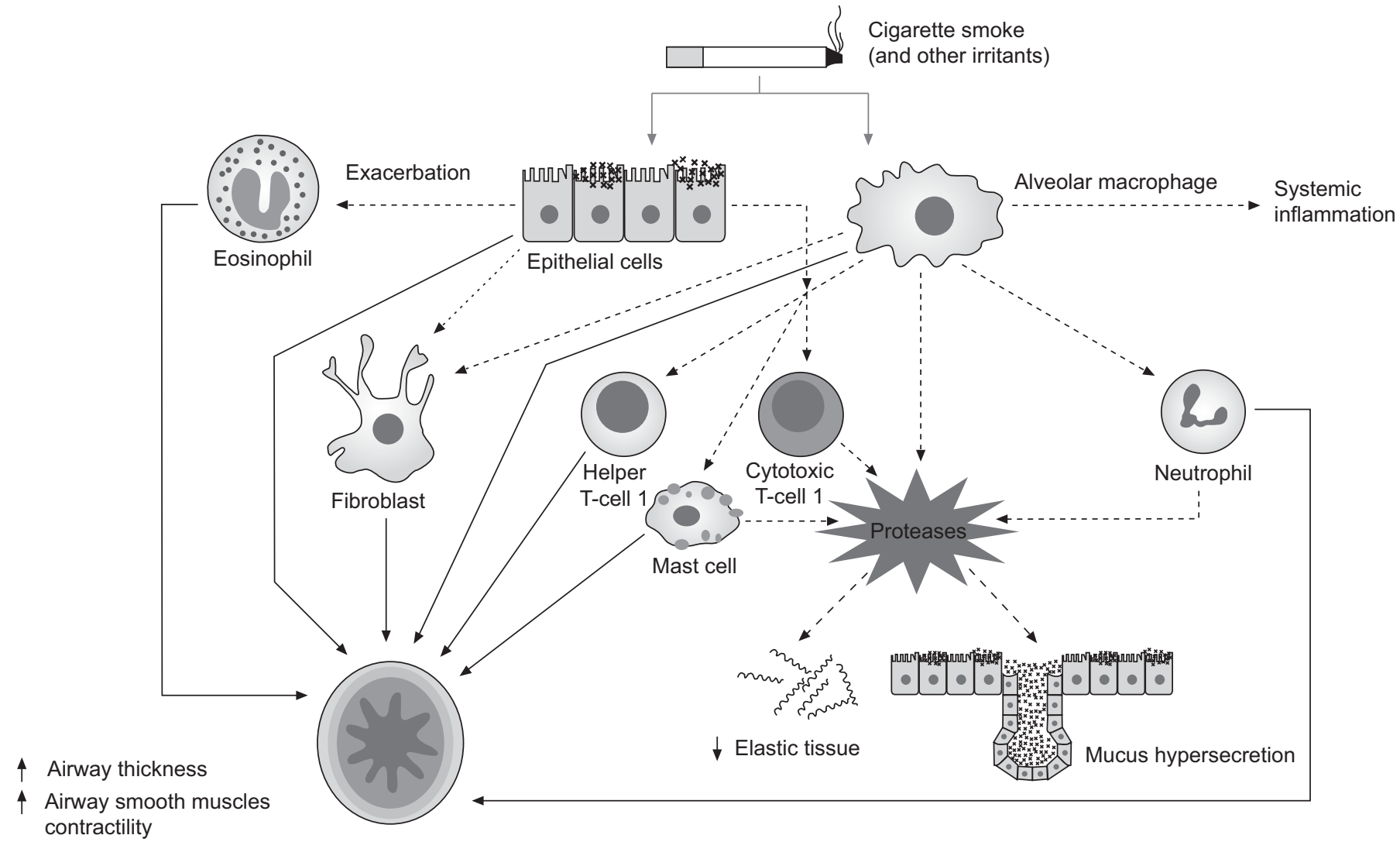

FIGURE 1. The four main pathophysiological mechanisms involved in the alteration of bronchial structure-function relationships in chronic obstructive pulmonary disease patients. Modified from [13] with permission from the publisher. 


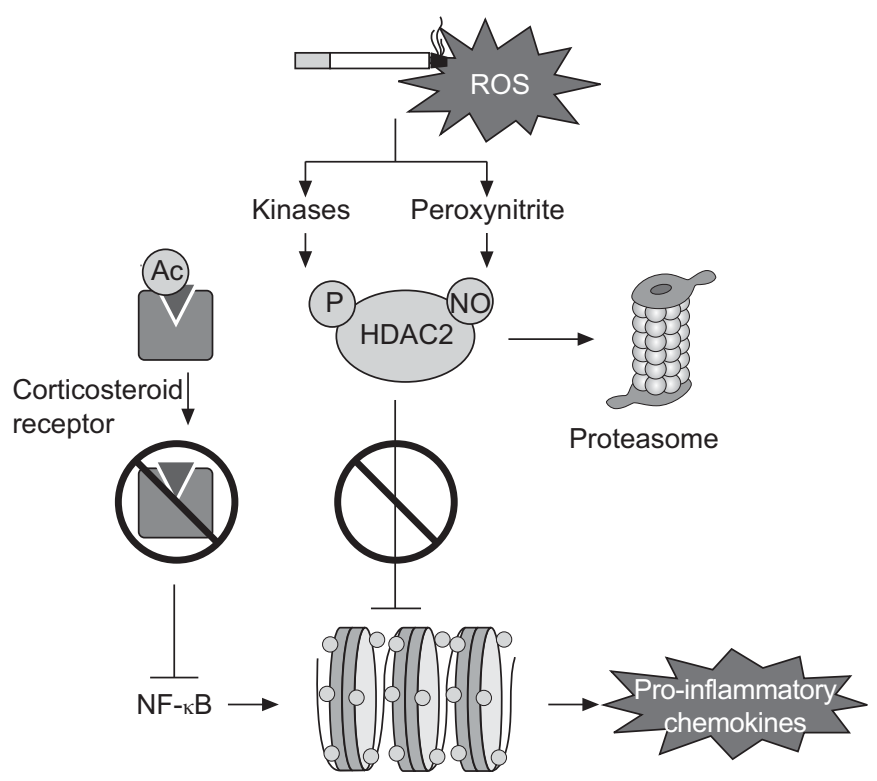

FIGURE 2. Oxidative stress and corticoresistance. Stimulation of alveolar macrophages by pro-inflammatory stimuli activates nuclear factor (NF)-кB and other transcription factors to switch on histone acetyltransferase, leading to histone acetylation and, subsequently, transcription of genes encoding pro-inflammatory chemokines. Corticosteroids reverse this by binding to glucocorticoid receptors and recruiting histone deacetylase (HDAC)2. In chronic obstructive pulmonary disease patients, cigarette smoke generates oxidative stress (acting through the formation of peroxynitrite). This impairs the activity of HDAC2. Consequently, the inflammatory response to NF-kB activation is amplified, and the anti-inflammatory effect of corticosteroids is reduced. ROS: reactive oxygen species. Modified from [17] with permission from the publisher.

extracellular matrix destruction; endothelial cell apoptosis; and triggering of the inflammation response. The determinants of extra- and intracellular redox control, which involve the mitochondrial function and antioxidant systems, are only partially known. Susceptibility genes and insufficient antioxidant system response with reduced levels of anti-ageing molecule are probably involved to varying degrees in accelerated progression of COPD. Indeed, oxidative stress accounts for certain similarities observed between the respiratory system alterations observed in COPD and cell ageing [16]. Finally, inflammatory cells (e.g. alveolar macrophages) in patients with COPD induce histone acetylase/deacetylase system dysfunction, which is sensitive to redox balance (fig. 2). As a consequence, reduced levels of histone deacetylase (HDAC)2 contribute to the impairment of cellular response to the antiinflammatory effects of corticosteroids, which has been observed in several in vitro studies [17].

While it is generally agreed that COPD inflammation is not restricted to the respiratory system, the relationships between pulmonary and systemic inflammation remain poorly known. However, the presence of some specific pulmonary inflammation markers in the bloodstream suggests extrapulmonary spread, although the respiratory and circulating levels of some mediators are not correlated. Previous studies have long shown increased plasma concentrations of inflammation markers (e.g. tumour necrosis factor (TNF)- $\alpha$ ) and other nonspecific mediators, such as acute-phase proteins (e.g. interleukin (IL)-6). The severity of systemic inflammation increases over time and with COPD exacerbations [18]. Systemic inflammation may be involved, to some degree, in the occurrence of some comorbidities associated with COPD, such as sarcopenia, diminished exercise tolerance, cardiovascular impairment, osteoporosis, anaemia, diabetes or depression.

Considering all the previously mentioned mechanisms, the molecular and cellular targets of inflammation and remodelling in COPD are many and various (table 1).

\section{COPD AND INFLAMMATION: DIFFERENT MECHANISMS FOR DIFFERENT PHENOTYPES}

The COPD population is notoriously heterogeneous. The variability in the risk of developing COPD and the number of different phenotypes argue for an individual genetic component; pangenomic studies have confirmed the importance of the antioxidant systems and the role of genes involved in angiogenesis. Cohort studies sought to distinguish patient phenotypes in terms of presenting characteristics and clinical evolution [19]. These phenotypes might be particularly associated with specific pathophysiological mechanisms responsive to some existing or expected treatments.

Although the differences between COPD with and without associated chronic bronchitis are not fully understood, proximal bronchial inflammation is associated with chronic bronchitis

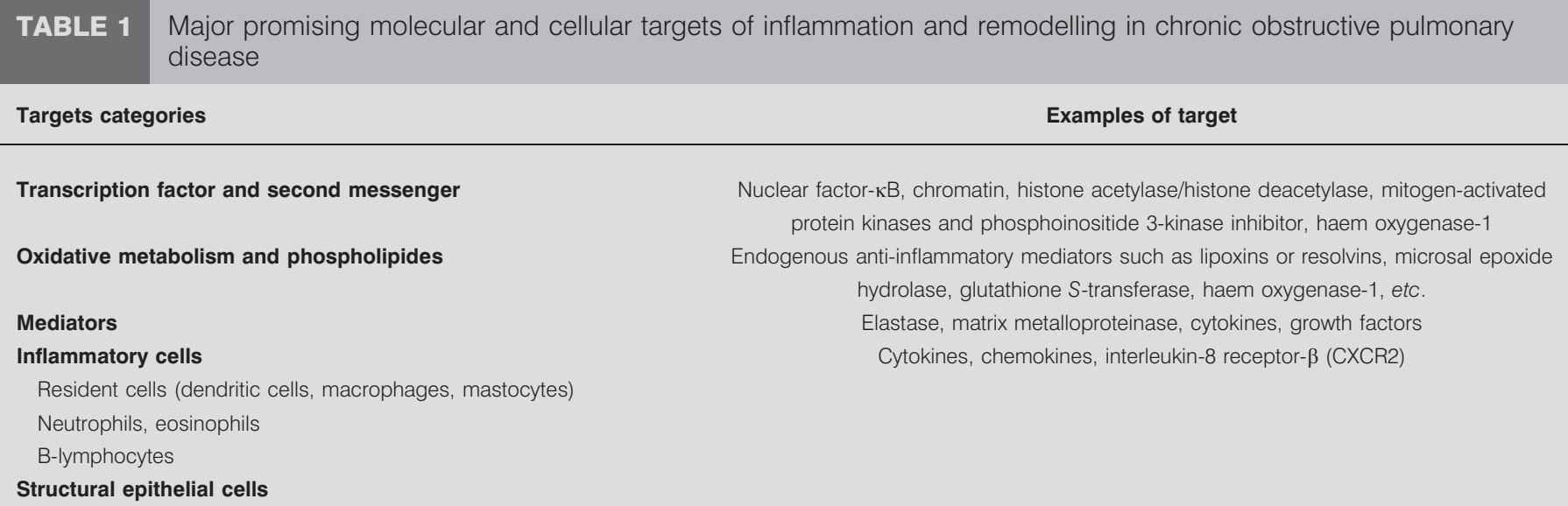


while small airway inflammation and remodelling correlate strongly with severity of obstruction. In smokers with COPD, central airway submucosal infiltration by macrophages and $\mathrm{T}$ lymphocytes (mainly CD8+) on bronchial biopsy is greater than in chronic bronchitis without obstructive respiratory disorder; more neutrophils are also found in the bronchial lumen [20, 21]. Furthermore, subjects with severe emphysema, compared to subjects without COPD, more often demonstrate tissue and lumen infiltration by various inflammatory cells (neutrophils, eosinophils, macrophages, and CD4 and CD8 T-lymphocytes) and a significant elevation in cells expressing adenovirus E1A protein, possibly implicating viral infection in the inflammatory infiltrate [22]. Airway computed tomography (CT) helps distinguishing two types of patients according to whether bronchial obstruction or emphysema predominates: areas of weak pulmonary attenuation on $\mathrm{CT}$, corresponding to emphysema, and bronchial wall thickening, correlating independently with measures of pulmonary obstruction [23]. There also seems to be a relationship between inflammation and bronchial and pulmonary lesions on the one hand, and dynamic hyperinflation on the other. A correlation was also demonstrated between elevated residual volume at rest and sputum neutrophilia with bronchial CD45+ cell infiltration [24, 25].

Exacerbation is a significant event in the course of COPD: patients may therefore be distinguished in terms of exacerbation history. The mean incidence of exacerbation varies from 0.5 to 3.5 per patient per year in published studies; so-called "frequent exacerbators" in general experience at least two exacerbations per year. Persistent elevated baseline inflammation (local and systemic) appears to be associated with frequent exacerbations. Other risk factors deserve investigation in cohort studies, such as mucus hypersecretion, degree of emphysema and hyperinflation, lower airway bacterial colonisation, characteristics of lower airway inflammation, COPD GOLD stage and other predictors of outcomes like the BODE index (body mass index, airflow obstruction, functional dyspnoea, exercise capacity), health-related quality of life and genetic factors [26-30].

Inflammatory cells, the number of which correlates with the degree of pulmonary endothelial dysfunction, are also found in the pulmonary artery wall of COPD patients, and the risk of pulmonary hypertension increases with the severity of low-grade systemic inflammation [31, 32]. The role of low-grade chronic inflammation in COPD comorbidity and, especially, in nutritional and muscular impairment, remains a matter of debate.

Altogether, although COPD is systematically associated with chronically impaired airflow, the causal mechanisms vary and the classic dichotomy between bronchial disease and emphysema is certainly an oversimplification.

\section{COPD AND INFLAMMATION: NEW DATA FOR NEW TREATMENTS}

Inhaled corticosteroids are recommended for the treatment of COPD only in combination with long-acting $\beta 2$-agonists, when forced expiratory volume in $1 \mathrm{~s}(\mathrm{FEV} 1)$ is $<50 \%$ predicted $(60 \%$ pred for the salmeterol-fluticasone combination according to European marketing authorisation) and when there is a history of frequent exacerbations. Although some in vitro studies found that in COPD patients (except those with asthma-like

TABLE $2 \begin{aligned} & \text { Biological mechanisms accounting for the } \\ & \text { possible reduced sensitivity to corticosteroids in } \\ & \text { chronic obstructive pulmonary disease }\end{aligned}$
Inflammation type
Implication of neutrophils
Signalling pathways
Excessive activation of transcription factors: nuclear factor- $\mathrm{\kappa B}$ and activator
protein-1
Increase in mitogen-activated protein kinase activity
Cooperation
Impairment of $\beta 2$-adrenoreceptor function
Imbalance in corticosteroid receptors (decreased $\alpha / \beta$ ratio)
Raised histone acetylation
Reduced histone-deacetylase expression
Inflammation and oxidative stress consequences

eosinophilic inflammation) [33] airway inflammation is much less sensitive to corticosteroids than in asthma (which may be due to several factors including decreased HDAC-2 activity) (table 2 and fig. 2) [17, 34], others demonstrated that these agents are able to reduce sputum neutrophils [35] and (at least when associated with long-acting $\beta 2$-agonists) decrease airway inflammation as assessed by bronchial biopsies [36]. Molecular co-operation between corticosteroids and $\beta 2$-agonists appears to be bidirectional, with corticosteroids increasing the transcription of the $\beta 2$-adrenoreceptor gene while $\beta 2$-agonists increase nuclear translocation of the glucocorticoid receptor following ligand fixation [37]. Clinically, the TORCH study (TOwards a Revolution in COPD Health) showed that inhaled corticosteroids associated with long-acting $\beta 2$-agonists decreased the frequency of exacerbations versus placebo $(-43 \%$ for moderate exacerbations, $-17 \%$ for severe exacerbations, $25 \%$ reduction altogether), salmeterol alone (-12\%), and fluticasone alone $(-9 \%)$, and improved quality of life $[1,38]$. The salmeterol-fluticasone combination did not provide a statistically significant effect on survival in the 3-yr TORCH study, which suggested a possible effect on FEV1 rate of decline [1,2]. Such an effect was not found in studies assessing the effect of inhaled corticosteroids alone, especially in milder COPD [39-41].

It has also been suggested that budesonide added to $\beta 2-$ agonists (formoterol) improves exercise tolerance [42]. However, the relevance of additional clinical effects provided by inhaled corticosteroids when added to long-acting $\beta 2$-agonists has been questioned [43]. In addition, although combinations of inhaled corticosteroids and long-acting bronchodilators may not be useful in all patients with severe COPD and exacerbations, available studies did not succeed in identifying a more selected subgroup of patients with clinically more relevant response [1]. Therefore, research aimed at developing other approaches to fight the inflammatory mechanisms involved in COPD is warranted.

Almost every year, reviews are published on treatment perspectives in COPD. Several classifications of lines of research seem to emerge, for example, according to whether the prime target is inflammation (cytokines, chemokines and cell adhesion molecules), protease/antiprotease or oxidant/ antioxidant balance, tissue repair (growth factors, retinoids and stem cells) or mucus hypersecretion. 
Airway mucus hypersecretion in COPD has been linked by pathological studies to hyperplasia of the mucin-producing proximal, and to a lesser extent to distal, bronchial epithelial goblet cells. Treatments targeting mucus hypersecretion can be classified into three types, according to whether they reduce mucin synthesis, reduce mucin secretion (e.g. antiproteases) or increase mucociliary clearance [44]. None of the available products targeting mucin secretion or synthesis has shown clinical efficacy. Molecules targeting mucin gel include $\mathrm{N}$-acetylcysteine (NAC) and its derivatives (carbocysteine, erdosteine and diacetylcysteine), recombinant surfactant and ambroxol. Only cysteines have undergone methodologically satisfactory clinical trials in COPD, and their impact on natural history remains controversial. The direct impact of NAC on mucin gel is highly uncertain: its potential effects may be related to its antioxidant activity [45]. A recent meta-analysis suggested that prolonged NAC treatment reduces COPD exacerbations, although this benefit was attenuated by concomitant inhaled corticosteroids [46].

Alveolar and bronchial elastic fibre degradation is a fundamental feature of COPD pathology, resulting from protease/ antiprotease imbalance characterised by increased production of elastolytic enzymes (e.g. neutrophil elastase, matrix metalloproteinase (MMP)-9 and MMP-12), neutrophils and macrophages and/or to antiprotease deficiency (e.g. $\alpha_{1}$-antitrypsin deficiency) [47]. Proteases also play a role in bronchial remodelling and mucus secretion. Among the elastolytic enzymes, MMP-12 would seem to play a prime role [48, 49]: its potential importance in COPD pathophysiology was recently confirmed in a genetic study in $>8,700$ patients with asthma or COPD [50]. Numerous serine-protease (e.g. neutrophil elastase) or matrix MMP inhibitors are under development for cancer or sepsis treatment, but none have yet shown clinical efficacy in COPD [51]. Low-dose erythromycin administered over a period of 1 year reduced COPD exacerbation frequency versus placebo [52]; this clinical effect may partly come from an antiprotease effect [51].

Macrophages and neutrophils secrete many mediators implicated in COPD, notably serine-proteases and MMPs, which are directly responsible for lung parenchymal degradation. Inflammatory cell recruitment is mediated by leukotriene $\mathrm{B}_{4}$ and by small peptides known as chemokines, which act by stimulating membrane receptors coupled to $G$ proteins $[53,54]$. More than 50 chemokines, classified as C, CC, CXC and CX3C, activate more than 20 known membrane receptors [55]; some activate a single type of receptor, while others can activate several. Receptor activation stimulates the signal transduction pathways underlying chemotaxis and also proliferation, differentiation and survival of inflammatory cells. The development of chemokine receptor antagonists would thus logically be relevant to reduce COPD inflammation $[56,57]$ by limiting the recruitment of inflammatory cells (in particular neutrophils) [57-59].

Theophylline has been shown in vitro to increase HDAC activity and response to corticosteroids [60]. Recently, FORD et al. [61] randomly allocated 30 patients to treatment by either: 1) oral placebo + inhaled placebo followed by oral low-dose theophylline ( $250 \mathrm{mg}$ b.i.d.) + inhaled placebo (4 weeks each, separated by a 2-week wash-out period), or 2) oral placebo + inhaled fluticasone (500 $\mu \mathrm{g}$ b.i.d.) followed by oral theophylline
+ inhaled fluticasone, with a 2-week open-label extension of the latter study arm in seven subjects. Theophylline plus fluticasone had greater effects on indices of airflow obstruction than theophylline alone, and in the open-label study extension theophylline added to fluticasone increased HDAC activity in peripheral blood monocytes. There was no difference between theophylline plus fluticasone and fluticasone alone in indices of airway inflammation [61]. Thus, in vivo evidence of a clinically relevant potentiation of the anti-inflammatory effects of fluticasone by theophylline remains limited.

Phosphodiesterase (PDE) 4 is expressed in most inflammatory and resident cells in the lungs. In COPD, the anti-inflammatory action of PDE-4 inhibitors has been explored in induced sputum: although it did not affect the percentage of inflammatory cells in induced sputum, treatment with PDE-4 inhibitor reduced the number of total cells, neutrophils and eosinophils, and the concentration of some inflammatory mediators in the sputum (IL-8, eosinophil cationic protein and neutrophil elastase) and in the serum (TNF- $\alpha$ ) [62]. In a biopsy study, a PDE-4 inhibitor reduced CD8+ and CD68+ (macrophages) cells in bronchial biopsies of COPD patients [63]. Recently, four phase-III clinical trials assessed the effect of PDE-4 inhibitor alone or in association with long-term bronchodilators versus placebo, or in association with a longterm bronchodilator versus the bronchodilator alone: the results were consistent throughout the studies, with a reduction of some $17 \%$ (nearly $21 \%$ in patients with concomitant treatment with a long-acting $\beta 2$-agonists) in moderate-to-severe exacerbation rates, which is clinically relevant in the studied population $[64,65]$.

Macrolides have not only antimicrobial but also immunomodulatory/anti-inflammatory effects; for instance, they decrease neutrophil activity and oxidant production and modulate cytokine production by airway epithelial cells [66]. Some studies suggested an effect of erythromycin on the frequency of exacerbations or common colds in patients with COPD [67]. Recently, results of a large 1-yr study with azithromycin ( $250 \mathrm{mg}$ per day) were reported: this macrolide reduced exacerbation frequency by $28 \%$ and improved quality of life [68]. Such results are undoubtedly encouraging, although azithromycin treatment was also more frequently associated with hearing impairment.

Statins also have anti-inflammatory effects. They reduce both the expression of surface adhesion molecules on endothelial cells, macrophages or eosinophils and of chemokine receptors, thereby reducing recruitment and migration of inflammatory cells such as neutrophils. Statins also reduce production of pro-inflammatory cytokines. In COPD patients, statins may significantly decrease all-cause mortality and exacerbation rate [69-71]. Exacerbation severity also decreases, with a significant fall in the number of intubations and in mortality associated with or following exacerbation [72-74]. Likewise, statins impact the decline in FEV1 [75, 76]. Finally, COPD patients receiving statins show improved exercise tolerance, with improvement in performance correlating with a reduction in C-reactive protein, suggesting an effect on peripheral inflammation [77]. The clinical usefulness of these findings remains limited, however, as most findings come from nonrandomised retrospective cohort studies. 
Peroxisome proliferator activated receptor (PPAR) agonists with anti-inflammatory properties are of increasing interest in the management of COPD $[78,79]$. In the lungs, PPAR- $\gamma$ activation inhibits pro-inflammatory cytokine secretion by macrophages and airway epithelial cells [78, 79]. It also induces T-lymphocyte apoptosis. PPAR $-\gamma$ agonists also reduce airway mucus production induced by cigarette smoke. In animal models of lipopolysaccharide-induced inflammation, rosiglitazone (a PPAR- $\gamma$ agonist) reduces neutrophil levels in the lung parenchyma but not in bronchoalveolar lavage [80]. The adverse cardiac effects of these molecules, however, limit their application, as COPD is frequently associated with cardiovascular comorbidity.

Several lines of research are therefore under way to develop new treatments which will act more effectively on symptoms, disability, rate of respiratory function deterioration and survival through more targeted focus on COPD-specific features of airway and systemic inflammation. One interesting aspect of current research is the growing awareness of the potential co-operation between different families of molecules.

\section{CONCLUSION}

Research into COPD inflammation is promising. Some lines of investigation will come to a dead end, while others will lead to new treatments, in some cases targeting very specific populations identified by clinical phenotyping or biomarkers. The arrival of PDE- 4 inhibitors and new data on macrolides or statins as anti-inflammatory treatments in COPD represent good illustrations of how knowledge of inflammatory and remodelling phenomena finally broadened the range of treatments able to improve patients' outcomes.

The arrival of new treatments, however, should by no means overshadow the other "unmet needs". COPD awareness needs to be fostered in the general population and among healthcare workers, as it is a key to improving detection, especially at early stages for which treatments of proven efficacy already exist. Screening strategies should thus become more efficient. Patient education should also be developed, to improve compliance and implement sustainable lifestyle changes. Access to optimally effective care and reinforcement of progress made should be promoted by developing rehabilitation structures. Improved synergy between primary and specialised care also requires more efficient implementation before patients fall into long-term invalidity.

\section{SUPPORT STATEMENT}

Nycomed (Paris, France) provided funding for the "Inflammation and COPD" meeting and for the development of this manuscript. The authors were involved with the entire process from design to critical revision of the manuscript, and maintained complete control over the direction and content of the paper. Nycomed did not have any influence on the manuscript content.

\section{STATEMENT OF INTEREST}

N. Roche received fees for speaking, organising education, or consulting from Altana Pharma, Nycomed, AstraZeneca, Boehringer Ingelheim, Chiesi, GlaxoSmithKline, MEDA, MSD-Chibret, Mundipharma, Novartis, Hoffman la Roche, Pfizer and Teva. He has received research grants from Nycomed and Boehringer Ingelheim. R. Marthan has received fees for speaking and travel to the ATS congress was funded by Nycomed. P. Berger received fees for speaking or consulting from Nycomed, Novartis, GlaxoSmithKline, AstraZeneca and Chiesi. He has received funds for research from Nycomed, Novartis and GlaxoSmithKline, and travel to the ERS and ATS congress was funded by Nycomed, Novartis, GlaxoSmithKline and Astra-Zeneca. A. Chambellan has received congress support from and/or served as a consultant for GlaxoSmithKline, Boehringer Ingelheim, Novartis and Nycomed. P. Chanez has provided consultancy services for Almirall, Boehringer Ingelheim, Centocor, GlaxoSmithKline, AstraZeneca, Novartis, Teva, Chiesi and Schering Plough; served on advisory boards for Almirall, Boehringer Ingelheim, Centocor, GlaxoSmithKline, AstraZeneca, Novartis, Teva, Chiesi and Schering Plough; received lecture fees from Almirall, Boehringer Ingelheim, Centocor, GlaxoSmithKline, AstraZeneca, Novartis, Teva, Chiesi and Schering Plough; and received industry-sponsored grants from Almirall, Boehringer Ingelheim, Centocor, GlaxoSmithKline, AstraZeneca, Novartis, Teva, Chiesi and Schering Plough. B. Aguilaniu has served as a consultant for Boehringer Ingelheim, Nycomed and Pfizer. P-Y. Brillet received fees for consulting from Nycomed and his travel to the 2010 ERS congress was funded by Nycomed. P-R. Burgel has received fees for speaking and consulting for Boehringer Ingelheim, Chiesi, GlaxoSmithKline, Novartis, Nycomed, AstraZeneca and Pfizer. P. Devillier has received fees for speaking, organising education, consulting research and congress support from AstraZeneca, Chiesi, GlaxoSmithKline, Novartis, Nycomed, Altana Pharma, Almirall, Boehringer Ingelheim, Stallergenes, Pfizer, Schering-Plough, and Merck Sharp and Dohme. R. Escamilla has served as a consultant for Boehringer Ingelheim, Chiesi, Novartis, Nycomed and Pfizer. R. Louis has served as a member of an advisory board for AstraZeneca, GlaxoSmithKline, Novartis, Nycomed, MSD and Chiesi, and received unrestricted research grants from AstraZeneca, GlaxoSmithKline and Novartis. J-F. Muir has received a fee for consulting from Nycomed, GlaxoSmithKline and Boehringer Ingelheim. T. Pérez has received fees for speaking at congresses from Chiesi, Novartis and Nycomed, fees for workshops by Chiesi and Nycomed, funding for academic research from Nycomed and Novartis, and is a consultant for AstraZeneca, Boehringer Ingelheim, Chiesi, GlaxoSmithKline, Novartis, Nycomed, Schering Plough and Pierre Fabre. His travel to ERS and CPLF congresses was funded by Chiesi, Nycomed, Boehringer Ingelheim and AstraZeneca. T. Similowski has received unrestricted research grants from Novartis and Maquet, lecture fees from Nycomed, Novartis, Boehringer Ingelheim, AstraZeneca, MSD and Medapharma, and has received honoraria from Nicomedia and Boehringer Ingelheim for organising education. He has received reimbursement for congresses expenses from Nycomed, Boehringer Ingelheim and AstraZeneca, and has received consulting fees from Nycomed, Novartis Boehringer Ingelheim, AstraZeneca and Pierre Fabre.

\section{ACKNOWLEDGEMENTS}

The author's affiliations are as follows. N. Roche: Service de Pneumologie et Réanimation, Université Paris Descartes, Assistance Publique-Hôpitaux de Paris, Hôtel-Dieu, Paris, France. R. Marthan and P. Berger: Service $\mathrm{d}$ 'Exploration Fonctionnelle Respiratoire, Centre Hospitalier Universitaire de Bordeaux, and Université de Bordeaux, INSERM U1045, Bordeaux, France. A. Chambellan: Service d'Exploration Fonctionnelle Respiratoire, Centre Hospitalier Universitaire de Nantes, and Université de Nantes, L'institut du thorax, INSERM UMR915, Nantes, France. P. Chanez: Département des Maladies Respiratoires, Assistance Publique-Hôpitaux de Marseille, and Université de la Méditerranée, Laboratoire d'Immunologie, INSERM CNRS U600, UMR6212, Marseille, France. B. Aguilaniu: Hylab, Clinique du Mail, Grenoble, France. P-Y. Brillet: Service de Radiologie, Assistance Publique-Hôpitaux de Paris, Hôpital Avicenne, and Université Paris 13, UPRES EA2363, Bobigny, France. P-R. Burgel: Pneumologie, Université Paris Descartes, Assistance Publique-Hôpitaux de Paris, Hôpital Cochin, Paris, France. A. Chaouat: Maladies Respiratoires, Centre Hospitalier Universitaire Brabois, Vandœuvre-lèsNancy, France. P. Devillier: Université Saint-Quentin en Yvelines, UPRES EA220, Hôpital Foch, Suresnes, France. R. Escamilla: Clinique des Voies Respiratoires, Hôpital Larrey, Toulouse, France. R. Louis: 
Pneumologie, Centre Hospitalier Universitaire de Liège, Domaine Universitaire du Sart Tilman, Liège, Belgium. H. Mal and M. Aubier: Service de Pneumologie A, Assistance Publique-Hôpitaux de Paris, Hôpital BichatClaude Bernard, and Faculté de Médecine de Paris Diderot, INSERM U700, Paris, France. J-F. Muir: Service de Pneumologie, Centre Hospitalier de Rouen, Hôpital de Bois-Guillaume, Rouen, France. T. Pérez and B. Wallaert: Service de Pneumologie et Immuno-Allergologie, Hôpital Calmette, Lille, France. T. Similowski Service de Pneumologie et Réanimation Médicale, Assistance Publique-Hôpitaux de Paris, Groupe Hospitalier Pitié-Salpêtrière, Université de Paris, Paris, France.

\section{REFERENCES}

1 Calverley PM, Anderson JA, Celli B, et al. Salmeterol and fluticasone propionate and survival in chronic obstructive pulmonary disease. N Engl J Med 2007; 356: 775-789.

2 Celli BR, Thomas NE, Anderson JA, et al. Effect of pharmacotherapy on rate of decline of lung function in chronic obstructive pulmonary disease: results from the TORCH study. Am J Respir Crit Care Med 2008; 178: 332-338.

3 Tashkin DP, Celli B, Senn S, et al. A 4-year trial of tiotropium in chronic obstructive pulmonary disease. $N$ Engl J Med 2008; 359: 1543-1554.

4 Aubier M, Marthan R, Berger P, et al. BPCO et inflammation: mise au point d'un group d'experts. Les mécanismes de l'inflammation et du remodelage [COPD and inflammation: statement from a French expert group: inflammation and remodelling mechanisms]. Rev Mal Respir 2010; 27: 1254-1266.

5 Pérez T, Mal H, Aguilaniu B, et al. BPCO et inflammation: mise au point d'un group d'experts. Les phénotypes en lien avec l'inflammation [COPD and inflammation: statement from a French expert group. Phenotypes related to inflammation]. Rev Mal Respir 2011; 28: 192-215.

6 Roche N, Devillier P, Aguilaniu B, et al. BPCO et inflammation: mise au point d'un group d'experts. Comment traiter l'inflammation? [COPD and inflammation: statement from a French expert group. How to treat inflammation?]. Rev Mal Respir 2011; 28: 427-442.

7 Saetta M, Di Stefano A, Maestrelli P, et al. Activated T-lymphocytes and macrophages in bronchial mucosa of subjects with chronic bronchitis. Am Rev Respir Dis 1993; 147: 301-306.

8 Hogg JC, Chu F, Utokaparch S, et al. The nature of small-airway obstruction in chronic obstructive pulmonary disease. $N$ Engl J Med 2004; 350: 2645-2653.

9 Cosio MG, Saetta M, Agusti A. Immunologic aspects of chronic obstructive pulmonary disease. N Engl J Med 2009; 360: 2445-2454.

10 Freeman CM, Martinez FJ, Han MK, et al. Lung dendritic cell expression of maturation molecules increases with worsening chronic obstructive pulmonary disease. Am J Respir Crit Care Med 2009; 180: 1179-1188.

11 Brusselle GG, Demoor T, Bracke KR, et al. Lymphoid follicles in (very) severe COPD: beneficial or harmful? Eur Respir J 2009; 34: 219-230.

12 van der Strate BW, Postma DS, Brandsma CA, et al. Cigarette smoke-induced emphysema: a role for the B cell? Am J Respir Crit Care Med 2006; 173: 751-758.

13 Barnes PJ. Emerging Pharmacotherapies for COPD. Chest 2008; 134: 1278-1286.

14 MacNee W. Pulmonary and systemic oxidant/antioxidant imbalance in chronic obstructive pulmonary disease. Proc Am Thorac Soc 2005; 2: 50-60.

15 Stevenson CS, Koch LG, Britton SL. Aerobic capacity, oxidant stress, and chronic obstructive pulmonary disease - a new take on an old hypothesis. Pharmacol Ther 2006; 110: 71-82.

16 Ito $\mathrm{K}$, Barnes PJ. COPD as a disease of accelerated lung aging. Chest 2009; 135: 173-180.

17 Barnes PJ, Adcock IM. Glucocorticoid resistance in inflammatory diseases. Lancet 2009; 373: 1905-17.
18 Donaldson GC, Seemungal TA, Patel IS, et al. Airway and systemic inflammation and decline in lung function in patients with COPD. Chest 2005; 128: 1995-2004.

19 Hurst JR, Vestbo J, Anzueto A, et al. Evaluation of COPD Longitudinally to Identify Predictive Surrogate Endpoints (ECLIPSE) investigators. Susceptibility to exacerbation in chronic obstructive pulmonary disease. N Engl J Med 2010; 363: 1128-1138.

20 Di Stefano A, Turato G, Maestrelli P, et al. Airflow limitation in chronic bronchitis is associated with T-lymphocyte and macrophage infiltration of the bronchial mucosa. Am J Respir Crit Care Med 1996; 153: 629-632.

21 O'Shaughnessy TC, Ansari TW, Barnes NC, et al. Inflammation in bronchial biopsies of subjects with chronic bronchitis: inverse relationship of CD8 T lymphocytes with FEV1. Am J Respir Crit Care Med 1997; 155: 852-857.

22 Retamales I, Elliott WM, Meshi B, et al. Amplification of inflammation in emphysema and its association with latent adenoviral infection. Am J Respir Crit Care Med 2001; 164: 469-473.

23 Nakano Y, Muro S, Sakai H, et al. Computed tomographic measurements of airway dimensions and emphysema in smokers. Correlation with lung function. Am J Respir Crit Care Med 2000; 162: 1102-1108.

24 O'Donnell RA, Peebles C, Ward JA, et al. Relationship between peripheral airway dysfunction, airway obstruction, and neutrophilic inflammation in COPD. Thorax 2004; 59: 837-842.

25 Turato G, Zuin R, Miniati M, et al. Airway inflammation in severe chronic obstructive pulmonary disease: relationship with lung function and radiologic emphysema. Am J Respir Crit Care Med 2002; 166: 105-110.

26 Patel IS, Seemungal TA, Wilks M, et al. Relationship between bacterial colonisation and the frequency, character, and severity of COPD exacerbations. Thorax 2002; 57: 759-764.

27 Bhowmik A, Seemungal TAR, Sapsford RJ, et al. Relation of sputum inflammatory markers to symptoms and lung function changes in COPD exacerbations. Thorax 2000; 55: 114-120.

28 Seemungal T, Harper-Owen R, Bhowmik A, et al. Respiratory viruses, symptoms, and inflammatory markers in acute exacerbations and stable chronic obstructive pulmonary disease. Am J Respir Crit Care Med 2001; 164: 1618-1623.

29 Baghai-Ravary R, Quint JK, Goldring JJ, et al. Determinants and impact of fatigue in patients with chronic obstructive pulmonary disease. Respir Med 2009; 103: 216-223.

30 Agustí AG, Noguera A, Sauleda J, et al. Systemic effects of chronic obstructive pulmonary disease. Eur Respir J 2003; 21: 347-360.

31 Growcott EJ, Spink KG, Ren X, et al. Phosphodiesterase type 4 expression and anti-proliferative effects in human pulmonary artery smooth muscle cells. Respir Res 2006; 7: 9.

32 Izikki M, Raffestin B, Klar J, et al. Effects of roflumilast, a phosphodiesterase-4 inhibitor, on hypoxia- and monocrotalineinduced pulmonary hypertension in rats. J Pharmacol Exp Ther 2009; 330: 54-62.

33 Chanez P, Vignola AM, O'Shaugnessy T, et al. Corticosteroid reversibility in COPD is related to features of asthma. Am J Respir Crit Care Med 1997; 155: 1529-1534.

34 Keatings V, Jatakanon A, Worsdell Y, et al. Effects of inhaled and oral glucocorticoids on inflammatory indices in asthma and COPD. Am J Respir Crit Care Med 1997; 155: 548.

35 Confalonieri M, Mainardi E, Della Porta R, et al. Inhaled corticosteroids reduce neutrophilic bronchial inflammation in patients with chronic obstructive pulmonary disease. Thorax 1998; 53: 583-585.

36 Barnes NC, Qiu YS, Pavord ID, et al. Anti-inflammatory effects of salmeterol/fluticasone propionate in chronic obstructive lung disease. Am J Respir Crit Care Med 2006; 173: 736-743.

37 Barnes PJ. Scientific rationale for inhaled combination therapy with long-acting $\beta 2$-agonists and corticosteroids. Eur Respir J 2002; 19: 182-191. 
38 Szafranski W, Cukier A, Ramirez A, et al. Efficacy and safety of budesonide/formoterol in the management of chronic obstructive pulmonary disease. Eur Respir J 2003; 21: 74-81.

39 Pauwels RA, Lofdahl CG, Laitinen LA, et al. Long-term treatment with inhaled budesonide in persons with mild chronic obstructive pulmonary disease who continue smoking. European Respiratory Society Study on Chronic Obstructive Pulmonary Disease. N Engl J Med 1999; 340: 1948-1953.

40 Burge PS, Calverley PM, Jones PW, et al. Randomised, double blind, placebo controlled study of fluticasone propionate in patients with moderate to severe chronic obstructive pulmonary disease: the ISOLDE trial. BMJ 2000; 320: 1297-1303.

41 Vestbo J, Sorensen $T$, Lange $P$, et al. Long-term effect of inhaled budesonide in mild and moderate chronic obstructive pulmonary disease: a randomised controlled trial. Lancet 1999; 353: 1819-1823.

42 Worth H, Förster K, Eriksson G, et al. Budesonide added to formoterol contributes to improved exercise tolerance in patients with COPD. Respir Med 2010; 104: 1450-1459.

43 Suissa S, Ernst P, Vandemheen KL, et al. Methodological issues in therapeutic trials of COPD. Eur Respir J 2008; 31: 927-933.

44 Fahy JV, Dickey BF. Airway mucus function and dysfunction. N Engl J Med 2010; 363: 2233-2247.

45 Chapron-Fouché J, Burgel PR. Mucolytics and other therapeutic agents targeting mucociliary clearance. In: EMC Pneumologie, ed. Paris, Elsevier Masson SAS, 2009; 6-000-P-010.

46 Poole PJ, Black PN. Mucolytic agents for chronic bronchitis or chronic obstructive pulmonary disease. Cochrane Database Syst Rev 2010; 2: CD001287.

47 Decramer M, Rutten-van Molken M, Dekhuijzen PN, et al. Effects of $\mathrm{N}$-acetylcysteine on outcomes in chronic obstructive pulmonary disease (Bronchitis Randomized on NAC Cost-Utility Study, BRONCUS): a randomised placebo-controlled trial. Lancet 2005; 365: 1552-1560.

48 Lee SH, Goswami S, Grudo A, et al. Antielastin autoimmunity in tobacco smoking-induced emphysema. Nat Med 2007; 13: 567-569.

49 Garbacki N, Di Valentin E, Piette J, et al. Matrix metalloproteinase 12 silencing: a therapeutic approach to treat pathological lung tissue remodeling? Pulm Pharmacol Ther 2009; 22: 267-278.

50 Hunninghake GM, Cho MH, Tesfaigzi Y, et al. MMP12, lung function, and COPD in high-risk populations. N Engl J Med 2009; 361: 2599-2608.

51 Djekic UV, Gaggar A, Weathington NM. Attacking the multitiered proteolytic pathology of COPD: new insights from basic and translational studies. Pharmacol Ther 2009; 121: 132-146.

52 Seemungal TA, Wilkinson TM, Hurst JR, et al. Long-term erythromycin therapy is associated with decreased chronic obstructive pulmonary disease exacerbations. Am J Respir Crit Care Med 2008; 178: 1139-1147.

53 Cowburn AS, Condliffe AM, Farahi N, et al. Advances in neutrophil biology: clinical implications. Chest 2008; 134: 606-612.

54 Jin $\mathrm{T}, \mathrm{Xu} \mathrm{X}$, Hereld D. Chemotaxis, chemokine receptors and human disease. Cytokine 2008; 44: 1-8.

55 Lukacs NW, Hogaboam CM, Kunkel SL. Chemokines and their receptors in chronic pulmonary disease. Curr Drug Targets Inflamm Allergy 2005; 4: 313-317.

56 Chapman RW, Phillips JE, Hipkin RW, et al. CXCR2 antagonists for the treatment of pulmonary disease. Pharmacol Ther 2009; 121: 55-68.

57 Donnelly LE, Barnes PJ. Chemokine receptors as therapeutic targets in chronic obstructive pulmonary disease. Trends Pharmacol Sci 2006; 27: 546-553.

58 Yamagata T, Ichinose M. Agents against cytokine synthesis or receptors. Eur J Pharmacol 2006; 533: 289-301.

59 Fitzgerald MF, Fox JC. Emerging trends in the therapy of COPD: novel anti-inflammatory agents in clinical development. Drug Discov Today 2007; 12: 479-486.
60 Cosio BG, Tsaprouni L, Ito K, et al. Theophylline restores histone deacetylase activity and steroid responses in COPD macrophages. J Exp Med 2004; 200: 689-695.

61 Ford PA, Durham AL, Russell REK, et al. Treatment effects of lowdose theophylline combined with an inhaled corticosteroid in COPD. Chest 2010; 137: 1338-1344.

62 Grootendorst DC, Gauw SA, Verhoosel RM, et al. Reduction in sputum neutrophil and eosinophil by the PDE4 inhibitor roflumilast in patients with COPD. Thorax 2007; 62: 1081-1087.

63 Gamble E, Grootendorst DC, Brightling CE, et al. Antiinflammatory effects of the phosphodiesterase-4 inhibitor cilomilast (Ariflo) in chronic obstructive pulmonary disease. Am J Respir Crit Care Med 2003; 168: 976-982.

64 Calverley PM, Rabe KF, Goehring UM, et al. Roflumilast in symptomatic chronic obstructive pulmonary disease: two randomized clinical trials. Lancet 2009; 374: 685-694.

65 Fabbri LM, Calverley PM, Izquierdo-Alonso JL, et al. Roflumilast in moderate-to-severe chronic obstructive pulmonary disease treated with long acting bronchodilators: two randomised clinical trials. Lancet 2009; 374: 695-703.

66 López-Boado YS, Rubin BK. Macrolides as immunomodulatory medications for the therapy of chronic lung diseases. Curr Opin Pharmacol 2008; 8: 286-291.

67 Seemungal TA, Wilkinson TM, Hurst JR, et al. Long-term erythromycin therapy is associated with decreased chronic obstructive pulmonary disease exacerbations. Am J Respir Crit Care Med 2008; 178: 1139-1147.

68 Albert RK, Bailey WC, Casaburi R, et al. Chronic azithromycin decreases the frequency of chronic obstructive pulmonary disease exacerbations. Am J Respir Crit Care Med 2011; 183: A6416.

69 Young RP, Hopkins R, Eaton TE. Potential benefits of statins on morbidity and mortality in chronic obstructive pulmonary disease: a review of the evidence. Postgrad Med J 2009; 85: 414-421.

70 Dobler CC, Wong KK, Marks GB. Associations between statins and COPD: a systematic review. BMC Pulm Med 2009; 9: 32.

71 Janda S, Park K, Fitzgerald M, et al. Statins in COPD. A systematic review. Chest 2009; 136: 734-743.

72 Blamoun AI, Batty GN, DeBari VA, et al. Statins may reduce episodes of exacerbation and the requirement for intubation in patients with COPD: evidence form a retrospective cohort study. Int J Clin Pract 2008; 62: 1373-1378.

73 Soyseth V, Brekke PH, Smith P, et al. Statin use is associated with reduced mortality of COPD. Eur Respir J 2007; 29: 279-283.

74 Mortensen EM, Copeland LA, Pugh MJV, et al. Impact of statins and ACE inhibitors on mortality after COPD exacerbations. Respir Res 2009; 10: 45.

75 Keddissi JI, Younis WG, Chbeir EA, et al. The use of statins and lung function in current and former smokers. Chest 2007; 132: 1764-1771.

76 Alexeeff SE, Litonjua AA, Sparrow D, et al. Statin use reduces decline in lung function: VA Normative Aging Study. Am J Respir Crit Care Med 2007; 176: 742-747.

77 Lee TM, Lin MS, Chang NC. Usefulnes of C-reactive protein and interleukin- 6 as predictors of outcomes in patients with chronic obstructive pulmonary disease receiving pravastatin. Am J Cardiol 2008; 101: 530-535.

78 Becker J, Delayre-Orthez C, Frossard N, et al. Regulation of inflammation by PPARs: a future approach to treat lung inflammatory diseases? Fundam Clin Pharmacol 2006; 20: 429-447.

79 Spears M, McSharry C, Thomson NC. Peroxisome proliferatoractivated receptors-gamma agonists as potential anti-inflammatory agents in asthma and chronic obstructive pulmonary disease. Clin Exp Allergy 2006; 36: 1494-1504.

80 Birrell MA, Patel HJ, McCluskie K, et al. PPAR-gamma agonists as therapy for diseases involving airway neutrophilia. Eur Respir J 2004; 24: 18-23. 